\title{
Pengaruh Sosialisasi Gerakan Masyarakat Hidup Sehat Terhadap Perilaku Konsumsi Buah Dan Sayur Pada Remaja
}

\author{
Theresia Ratih Ayu Budiwati, Terry Yuliana, Agustina, Yuri Nurdiantami \\ Program Studi S1 Kesehatan Masyarakat, Fakultas Ilmu Kesehatan \\ Universitas Pembangunan Nasional Veteran Jakarta
}

\begin{abstract}
Abstrak
Latar belakang : Konsumsi buah dan sayur merupakan salah satu kegiatan gerakan masyarakat hidup sehat (GERMAS) yang perlu diperhatikan untuk mewujudkan gizi seimbang, khususnya bagi remaja yang sedang mengalami proses pertumbuhan dan perkembangan. Kekurangan konsumsi buah dan sayur dapat mengakibatkan berbagai masalah, salah satunya adalah masalah gizi yang banyak dijumpai pada remaja. Studi ini bertujuan untuk mengetahui pengaruh sosialisasi GERMAS melalui metode ceramah, pemaparan PowerPoint, video, dan benda asli terhadap perilaku konsumsi buah dan sayur pada siswa SMP Kasih Depok.

Metode: Penelitian ini menggunakan desain pre eksperimental, teknik pengambilan sampel dengan purposive sampling. Sampel sebanyak 67 siswa. Analisis data menggunakan analisis univariat dan bivariat dengan Uji Wilcoxon pada tingkat kepercayaan 95\% $(\alpha=0,05)$.

Hasil: Didapatkan nilai p-value 0,000 pada variabel pengetahuan, sikap, dan tindakan siswa terhadap konsumsi buah dan sayur.

Kesimpulan: Ada perbedaan dan pengaruh pemberian sosialisasi GERMAS melalui ceramah, pemaparan PowerPoint, video dan benda asli terhadap GERMAS, pengetahuan terhadap konsumsi buah dan sayur, sikap, dan tindakan.
\end{abstract}

Kata Kunci: buah, pengetahuan, sayur, sikap, tindakan

\section{The Effect Of Gerakan Masyarakat Hidup Sehat (Germas) Socialization On Fruit And Vegetable Consumption Behavior For Teenagers}

\begin{abstract}
Background: Fruit and vegetable consumption is one of Gerakan Masyarakat Hidup Sehat (GERMAS) activity that need to be considered to realize the balance of nutrition, especially for adolescents who are experiencing the process of growth and development. The deficiency of fruit and vegetable consumption will lead the adolescents to various problems, one of them is nutritional problem that often find in adolescents. This study aims to determine the effect of GERMAS socialization through lectures, PowerPoint presentations, videos, and real objects on fruit and vegetable consumption behavior in SMP Kasih Depok.

Methods: this study use pre-experimental design, with purposive sampling technique. Samples were 67 students. Data analysis were using univariate and bivariate analysis with Wilcoxon Test at confidence level of $95 \%(\alpha=0.05)$.

Result: The p-value was 0,000 on knowledge, attitude and action toward fruit and vegetable consumption.

Conclusion: There were significant differences and effects of GERMAS socialization through lectures, PowerPoint, video presentations and real objects on knowledge variable of GERMAS, knowledge variable of fruit and vegetable consumption, attitude variable, and action variable. The use of several media on socialization would more effective than just using one media.
\end{abstract}

Keywords: action, attitude, fruit, knowledge, vegetable

Alamat Korespondensi :

Theresia Ratih Ayu Budiwati

Fakultas Ilmu Kesehatan, Universitas Pembangunan

Nasional Veteran Jakarta, Jl. Raya Limo, Depok

Email: ratihthera@gmail.com 


\section{PENDAHULUAN}

Pola makan yang sehat adalah usaha seseorang dalam mengatur jumlah dan jenis makanan untuk mempertahankan kesehatan tubuhnya, menyeimbangkan asupan gizi yang dibutuhkan tubuh, mencegah terserangnya penyakit, serta membantu kesembuhan penyakit1. Pola makan dapat mempengaruhi keadaan gizi seseorang, sehingga pola makan yang baik harus berpedoman pada Gizi Seimbang.

Pada tahun 2015, sebesar $65,2 \%$ remaja sering melewati waktu sarapan dan sebesar 75,7\% remaja sering mengkonsumsi makanan dengan bumbu penyedap. Pada tahun 2013, di Jawa Barat didapatkan $96,4 \%$ penduduk usia diatas 10 tahun kurang mengonsumsi buah dan sayur serta mengalami peningkatan menjadi $98,2 \%$ pada tahun 2018. Sebuah penelitian yang dilakukan di Bogor pada tahun 2018 mendapatkan hasil bahwa sebanyak 13 dari 15 orang tua mengaku bahwa anak mereka sulit mengonsumsi buah dan sayur ${ }^{5}$, serta penelitian yang dilakukan di Kuantan Hilir pada tahun 2015 mendapatkan hasil bahwa sebesar 28,42\% responden kurang mengonsumsi buah dan sayur ${ }^{6}$.

Untuk mewujudkan gizi yang seimbang, konsumsi buah dan sayur perlu diperhatikan. Buah dan sayur tidak dapat dipisahkan karena keduanya mengandung zat gizi mikro seperti vitamin, mineral, dan serat yang berperan dalam peningkatan metabolisme dan menjaga kekebalan tubuh ${ }^{7}$. Konsumsi buah dan sayur yang dianjurkan oleh World Health Organization (WHO) adalah sebesar 400 gram per orang per hari yang terdiri dari 150 gram buah dan 250 gram sayur ${ }^{8}$.

Gerakan Masyarakat Hidup Sehat atau GERMAS merupakan program kesehatan untuk meningkatkan derajat kesehatan masyarakat salah satunya melalui konsumsi buah dan sayur setiap hari, terutama pada remaja yang sedang mengalami proses pertumbuhan dan perkembangan. Remaja sebagai usia bermasalah perlu mendapatkan perhatian lebih dalam memilih makanan. Untuk itu dilakukan sosialisasi GERMAS untuk dapat meningkatkan pengetahuan, sikap, dan tindakan remaja khususnya dalam mengonsumsi buah dan sayur. Sosialisasi tersebut dilakukan di SMP Kasih Depok yang belum pernah mendapatkan sosialisasi terkait GERMAS.

\section{METODE}

Penelitian ini dilakukan di SMP Kasih Depok pada bulan Mei 2019. Desain penelitian menggunakan pre eksperimental dengan rancangan one group pre test and post test untuk mengukur pengetahuan, sikap dan tindakan dalam mengonsumsi buah dan sayur melalui sosialisasi dengan metode ceramah, pemaparan PowerPoint, video dan benda asli.

Sampel didapat sebanyak 67 menggunakan teknik purposive sampling. Pengumpulan data dilakukan melalui pengisian kuesioner oleh responden dan dianalisis melalui analisis univariat dan bivariat. Analisis univariat meliputi jenis kelamin, uang saku, kegiatan ekstrakurikuler dan Indeks Massa Tubuh (IMT). Analisis bivariat meliputi pengetahuan, sikap dan tindakan terhadap konsumsi buah dan sayur menggunakan Uji Wilcoxon. Variabel tindakan dievaluasi satu minggu setelah sosialisasi menggunakan google form.

\section{HASIL}

\section{Analisis Univariat}

Berdasarkan sampel 67 siswa, didapatkan karakteristik responden antara lain Jenis Kelamin, Uang Saku, Kegiatan Ekstrakurikuler, dan IMT. (Tabel 1).

Tabel 1. Distribusi Frekuensi

\section{Responden Berdasarkan Karakteristik}

Karakteristik Responden Jumlah

$\%$

$\begin{array}{lll}\text { Jenis Kelamin } & & \\ \text { - Laki-laki } & 34 & 50,7 \\ \text { - Perempuan } & 33 & 49,3 \\ \text { - Total } & 67 & 100\end{array}$

\section{Uang Saku}

- Tinggi ( $(<\mathrm{Rp} 10.179$ per hari) $\quad 19 \quad 28,4$

- Rendah (<Rp10.179 per hari) $\quad 48 \quad 71,6$

- Total

$67 \quad 100$

\section{Kegiatan Ekstrakurikuler}

- Fisik (Paskibra, Pramuka,

Basket, Futsal,

Silat/Taekwondo)

- Non Fisik (Paduan Suara) $11 \quad 10,4$

- Tidak mengikuti

$14 \quad 20,9$

- Total

$67 \quad 100$

\section{IMT}

- Kurang $(<18,5)$

- Normal $(18,5-22,9)$

- Lebih ( $\geq 23)$

- Total

$19 \quad 28,4$

$33 \quad 49,3$

$15 \quad 22,4$

$67 \quad 100$


Berdasarkan hasil analisis univariat pada variabel jenis kelamin menunjukkan bahwa pada responden dengan jenis kelamin laki-laki menunjukkan jumlah terbanyak yaitu 34 responden $(50,7 \%)$. Pada variabel uang saku menunjukkan terbanyak pada kategori rendah dengan jumlah terbanyak yaitu 48 responden $(71,6 \%)$. Pada variabel kegiatan ekstrakurikuler menunjukkan bahwa jumlah terbanyak terdapat pada responden dengan kegiatan ektrakurikuler fisik (Paskibra, Pramuka, Basket, Futsal, Silat/Taekwondo) yaitu sebanyak 42 responden $(62,7 \%)$. Pada variabel IMT (Indeks Masa Tubuh) menunjukkan bahwa sebagian besar responden dengan kategori Normal yaitu sebanyak 33 responden $(49,3 \%)$.

Tabel 2. Pengaruh Sosialisasi GERMAS terhadap Perilaku Konsumsi Buah dan Sayur

\begin{tabular}{|c|c|c|c|c|c|c|}
\hline \multicolumn{7}{|c|}{ Rank } \\
\hline Variabel & Mean & SD & Min & Max & $p$-value & $\mathbf{N}$ \\
\hline \multicolumn{7}{|l|}{ Pengetahuan } \\
\hline Sebelum Sosialisasi & 7,69 & 1,663 & 1 & 11 & 0,000 & 67 \\
\hline Sesudah Sosialisasi & 9,21 & 1,513 & 5 & 11 & & \\
\hline \multicolumn{7}{|c|}{ Rank } \\
\hline Variabel & Mean & SD & Min & Max & p-value & $\mathbf{N}$ \\
\hline
\end{tabular}

Sikap

$\begin{array}{lllllll}\text { Sebelum Sosialisasi } & 6,31 & 1,384 & 0 & 8 & 0,000 & 67 \\ \text { Sesudah Sosialisasi } & 7,25 & 1,106 & 4 & 8 & & \end{array}$

Tindakan

$\begin{array}{lllllll}\text { Sebelum Sosialisasi } & 3,37 & 1,849 & 0 & 7 & 0,000\end{array}$

$\begin{array}{lllll}\text { Sesudah Sosialisasi } & 4,55 & 1,540 & 0 & 7\end{array}$

Berdasarkan uji statistik didapatkan perbedaan pengetahuan siswa SMP Kasih Depok terhadap konsumsi buah dan sayur sebelum dan sesudah dilakukan sosialisasi GERMAS sebesar 1,52 dengan p-value 0,000 $(<0,05)$, bahwa ada pengaruh sosialisasi GERMAS terhadap pengetahuan konsumsi buah dan sayur pada siswa SMP Kasih Depok.

Berdasarkan uji statistik didapatkan pvalue $0,000(<0,05)$, yang berarti ada pengaruh sosialisasi GERMAS melalui ceramah, pemaparan PowerPoint, video dan benda asli terhadap sikap konsumsi buah dan sayur pada siswa SMP Kasih Depok.

Berdasarkan uji statistik ada perbedaan tindakan siswa SMP Kasih Depok terhadap konsumsi buah dan sayur sebelum dan sesudah dilakukan sosialisasi GERMAS sebesar 1,18 dengan p-value $0,000(<0,05)$, yang berarti ada pengaruh sosialisasi GERMAS melalui ceramah, pemaparan PowerPoint, video dan benda asli.

\section{PEMBAHASAN}

Perbedaan Pengetahuan Responden terhadap Konsumsi Buah dan Sayur Sebelum dan Sesudah Sosialisasi

Pengetahuan merupakan hasil tahu setelah seseorang melakukan pengindraan terhadap suatu objek yang didapat dari proses penyampaian informasi9. Proses penyampaian materi konsumsi buah dan sayur melibatkan indra pengelihatan, peraba, perasa dan pendengaran. Indra pengelihatan dan pendengaran diperoleh melalui penayangan slide PowerPoint dan video konsumsi buah dan sayur, sementara indra peraba dan perasa didapatkan melalui penampilan contoh benda asli yaitu piring makanku yang dibuat dalam dua contoh, yaitu contoh piring pertama terdiri dari nasi sebagai makanan pokok, ikan bandeng sebagai lauk-pauk, buah pisang dan sayur capcay. Pada contoh piring kedua terdiri dari kentang rebus sebagai makanan pokok, tempe goreng sebagai lauk-pauk, buah jeruk dan berbagai sayuran yang direbus. Contoh piring makanku ditampilkan dengan menyesuaikan porsi sekali makan yang telah ditetapkan oleh kemenkes, yaitu setengah porsi dari piring makan terdiri dari buah dan sayur. Indra perasa pada penelitian ini dilibatkan melalui pemberian buah-buahan berupa pisang dan jeruk sesudah sosialisasi dilaksanakan.

Berdasarkan kerucut pengalaman Edgar Dale, benda asli memiliki intensitas paling tinggi dalam menyampaikan informasi, sehingga dapat meningkatkan pengetahuan siswa terhadap konsumsi buah dan sayur secara lebih maksimal karena melibatkan lebih banyak alat indra ${ }^{10}$. Alat indra manusia merupakan faktor yang memegang peranan penting dalam proses 
penerimaan informasi. Alat indra akan menangkap setiap stimulus yang datang dari luar tubuh manusia dan kemudian akan ditafsirkan di dalam otak, serta merangsang otak untuk mengolah informasi tersebut sehingga dapat mempengaruhi seseorang dalam berperilaku ${ }^{11}$.

Berdasarkan uji statistik didapatkan perbedaan pengetahuan siswa SMP Kasih Depok terhadap konsumsi buah dan sayur sebelum dan sesudah dilakukan sosialisasi GERMAS sebesar 1,52 dengan p-value 0,000 $(<0,05)$, bahwa ada pengaruh sosialisasi GERMAS terhadap pengetahuan konsumsi buah dan sayur pada siswa SMP Kasih Depok.

Hasil penelitian ini sejalan dengan penelitian yang dilakukan oleh Sibagariang (2016) dengan hasil penelitian ada pengaruh pemberian penyuluhan dengan metode ceramah terhadap pengetahuan siswa tentang konsumsi buah dan sayur di Kota Medan ${ }^{12}$. Demikian halnya dengan penelitian yang dilakukan Rahayu (2016) di Pasuruan dengan hasil terdapat perbedaan yang signifikan tingkat pengetahuan konsumsi buah dan sayur sesudah dilakukan edukasi gizi melalui metode ceramah. Namun menurut Rahayu (2016), peningkatan pengetahuan akan lebih efektif lagi jika edukasi dibarengi dengan kegiatan praktik karena kegiatan praktik melibatkan banyak alat indra sehingga pengetahuan yang diperoleh juga akan semakin banyak ${ }^{13}$.

Penerimaan materi mengenai konsumsi buah dan sayur sebagai salah satu proses belajar merupakan faktor yang dapat mempengaruhi perkembangan remaja. Seseorang yang sering terpapar informasi hidup sehat sejak dini dan didukung oleh pelatihan secara terus menerus, maka tidak menutup kemungkinan orang tersebut dapat menerapkan hidup sehat, khususnya konsumsi buah dan sayur yang dapat berdampak positif terhadap pertumbuhan dan perkembangan yang baik pada masa remaja ${ }^{14}$.

\section{Perbedaan Sikap Responden Sebelum dan Sesudah Sosialisasi GERMAS}

Berdasarkan uji statistik didapatkan ada perbedaan sikap siswa SMP Kasih Depok terhadap konsumsi buah dan sayur sebelum dan sesudah dilakukan sosialisasi GERMAS. Sebagian besar siswa $(71,6 \%)$ menerima dan memperhatikan materi konsumsi buah dan sayur dengan baik. Siswa dapat merespon, memberikan tanggapan saat peneliti menyampaikan materi dan menjawab pertanyaan-pertanyaan, namun sebagian besar siswa mengaku tidak mendapat ajakan dari teman sebayanya untuk makan buah dan sayur. Dalam hal ini siswa belum mencapai tingkatan sikap yang ketiga, yaitu menghargai. Sikap merupakan respon seseorang terhadap sesuatu yang tidak dapat dilihat secara langsung, namun dapat ditafsirkan terlebih dahulu melalui perilaku tertutup ${ }^{9}$. Dalam hal ini, sikap dapat diartikan sebagai kesediaan seseorang untuk melakukan suatu tindakan. Teori Allport menerangkan bahwa sikap seseorang terdiri dari empat tingkatan yang dimulai dari tingkatan paling rendah hingga paling tinggi, yaitu: menerima, merespon, menghargai hingga bertanggung jawab?

Berdasarkan uji statistik didapatkan pvalue $0,000(<0,05)$, yang berarti ada pengaruh sosialisasi GERMAS melalui ceramah, pemaparan PowerPoint, video dan benda asli terhadap sikap konsumsi buah dan sayur pada siswa SMP Kasih Depok. Hasil penelitian ini didukung oleh Gustiara (2013) yang melakukan penelitian deskriptif di Pekanbaru dengan hasil seluruh responden memiliki tingkat pengetahuan yang baik dan hampir seluruh responden memiliki sikap yang baik ${ }^{15}$. Demikian dengan hasil yang didapatkan pada penelitian ini, terjadi peningkatan antara pengetahuan dan sikap pada saat sebelum dan sesudah dilakukan sosialisasi.

Pengetahuan merupakan domain perilaku yang paing penting karena digunakan sebagai dasar seseorang dalam mengambil keputusan dan menentukan tindakan ${ }^{10}$. Proses penerimaan informasi harus dilakukan secara menyeluruh dimulai dari aspek kognitif, afektif, dan psikomotor yang tidak dapat dipisahkan satu sama lain, karena setiap aspek akan berdampak pada aspek yang lain, demikian halnya tanpa pengetahuan yang cukup maka seseorang tidak akan kesulitan untuk menilai hal baik maupun buruk.

\section{Perbedaan Tindakan Responden Sebelum dan Sesudah Sosialisasi}

Tindakan merupakan aksi nyata atau terwujudnya suatu sikap dalam diri seseorang yang memerlukan faktor dukungan dari pihak lain $^{16}$. Dukungan tersebut dapat berasal dari keluarga, teman, lingkungan, maupun diri sendiri. Untuk mencapai perubahan tindakan diperlukan waktu, baik secara cepat maupun lambat tergantung dari dukungan yang diterima ${ }^{17}$. Seseorang dengan pengetahuan terhadap konsumsi buah dan sayur yang baik belum tentu memiliki kecenderungan untuk mengambil tindakan dalam mengonsumsi buah dan sayur. Menurut penelitian deskriptif di Kota 
Palembang oleh Virlita (2015), pengetahuan tidak memiliki pengaruh yang besar terhadap tingkat konsumsi serat pada remaja ${ }^{18}$. Pengetahuan merupakan reaksi pasif seseorang terhadap sesuatu yang berasal dari dalam diri sendiri. Untuk dapat merubah perilaku pada seseorang yang telah mengalami proses belajar, diperlukan dukungan dari luar yaitu dukungan keluarga, teman, maupun lingkungan ${ }^{19}$.

Berdasarkan uji statistik ada perbedaan tindakan siswa SMP Kasih Depok terhadap konsumsi buah dan sayur sebelum dan sesudah dilakukan sosialisasi GERMAS sebesar 1,18 dengan p-value 0,000 $(<0,05)$, yang berarti ada pengaruh sosialisasi GERMAS melalui ceramah, pemaparan PowerPoint, video dan benda asli. Untuk dapat memberikan perubahan perilaku pada setiap orang, diperlukan strategi perubahan. Penelitian ini menggunakan strategi perubahan melalui edukasi, yaitu penyampaian sosialiasi GERMAS kepada siswa. Penyampaian sosialisasi berhasil meningkatkan dan memberikan pengaruh terhadap pengetahuan, sikap, dan tindakan siswa dalam mengonsumsi buah dan sayur. Namun agar dapat merubah tindakan seseorang secara maksimal tidak cukup jika hanya melalui satu kali penyampaian edukasi, diperlukan motivasi, kemampuan, penghargaan, serta program komunikasi multisektor yang dilakukan secara berkelanjutan, seperti meminta bantuan kepada para guru untuk memantau tindakan siswa dalam mengonsumsi buah dan sayur, maupun dikeluarkannya kebijakan sekolah agar siswa membawa bekal sehat setiap hari ${ }^{20}$.

Teori Lawrence Green dalam mengungkapkan bahwa dalam mempengaruhi perubahan perilaku, diperlukan beberapa faktor, yaitu faktor predisposisi, faktor pendukung, dan faktor penguat9. Sikap merupakan salah satu faktor predisposisi, namun berdasarkan hasil penelitian sebanyak $80,6 \%$ siswa dengan sikap positif tidak sepenuhnya memiliki tindakan dalam mengonsumsi buah dan sayur. Hal tersebut dikarenakan siswa SMP Kasih Depok hanya mencapai tingkatan sikap yang kedua, yaitu merespon. Artinya siswa hanya mampu memberikan tanggapan atas apa yang diberikan, namun belum dapat mengajak dan mendiskusikan suatu masalah dengan orang lain. Dukungan baik dari keluarga, teman sebaya, maupun lingkungan, serta kebijakan-kebijakan mengenai konsumsi makanan sehat sangat diperlukan untuk meningkatkan peluang siswa dalam mengonsumsi buah dan sayur.

Konsumsi buah dan sayur sangat diperlukan untuk mewujudkan gizi yang seimbang karena keduanya mengandung zat gizi mikro seperti vitamin, mineral, dan serat yang berperan dalam peningkatan metabolisme dan menjaga kekebalan tubuh ${ }^{15}$. Kurangnya konsumsi buah dan sayur dapat berdampak pada terganggunya masalah gizi remaja, seperti anemia, KEK, dan obesitas, sementara masa remaja merupakan periode yang paling penting karena pada masa ini terjadi pertumbuhan fisik dan perkembangan kognitif yang sangat cepat. Pada masa pertumbuhan dan perkembangan, diharapkan remaja memiliki gizi yang sehat karena kegagalan dalam masa ini dapat berdampak hingga dewasa dan menimbulkan berbagai kesehatan ${ }^{21}$. Pada remaja perempuan akan menjadi calon ibu, sehingga diperlukan untuk mempertahankan keadaan sehat agar kelak dapat melahirkan anak yang sehat dan $\operatorname{cerdas}^{22}$.

\section{KESIMPULAN}

Dapat disimpulkan bahwa sebelum dan sesudah dilakukan sosialisasi GERMAS terdapat perbedaan pengetahuan siswa terhadap konsumsi buah dan sayur sebesar 1,52 dengan $\mathrm{p}$ value $0,000 \quad(<0,05)$, sikap siswa terhadap konsumsi buah dan sayur dengan p-value 0,000 $(<0,05)$, dan tindakan siswa terhada Berdasarkan uji statistik ada perbedaan tindakan siswa terhadap konsumsi buah dan sayur sebesar 1,18 dengan p-value $0,000(<0,05)$, yang berarti ada pengaruh sosialisasi GERMAS melalui ceramah, pemaparan PowerPoint, video dan benda asli. Hasil uji statistik pada sikap menunjukkan hasil p-value $(0,000)$ lebih kecil dari 0,05 dapat disimpulkan terdapat perbedaan pengetahuan, sikap, dan tindakan terhadap konsumsi buah dan sayur sebelum dan sesudah diberikan sosialisasi GERMAS pada siswa.

Saran yang dapat peneliti berikan setelah diadakannya penelitian ini antara lain yaitu memberikan promosi kesehatan secara berkala dan merata mengenai Sosialisasi Gerakan Masyarakat Hidup Sehat (GERMAS) sehingga pengetahuan, sikap dan tindakan remaja menjadi lebih baik dalam mengonsumsi buah dan sayur.

\section{DAFTAR PUSTAKA}

1. Adriani, M. dan Writjamadi, B. Gizi dan Kesehatan Balita: Peranan Mikro Zinc. Jakarta: Kencana; 2014.

2. Kemenkes. Kenali Masalah Gizi yang Ancam Remaja Indonesia. Jakarta: Kementerian Kesehatan RI; 2018.

3. Priherdityo, E. Konsumsi Buah Indonesia Paling Rendah Se-Asia [online]. Jakarta; 
2016.

Tersedia

pada:

https://www.cnnindonesia.com/gaya-

hidup/20160526032604-262-133498/

konsumsi-buah-indonesia-paling-rendah-seasia (Diakses: 2 April 2019).

4. Muaris, H. J. Bahaya Buah dan Sayuran + Panduan Konsumsi yang Benar. Jakarta: Gramedia Pustaka Utama; 2014.

5. Lubis, A. C. dan Sekarasih, L. Dukungan Orang Tua kepada Remaja di Kota Bogor untuk Mengonsumsi Sayur dan Buah. Media Gizi Indonesia. 2018:13(2).

6. Endrika, A., dkk. Kecukupan Konsumsi Sayur dan Buah pada Siswa SMA Negeri 1 Kuantan Hilir, J FK. 2017; 2(2).

7. Kemenkes. Kenali Masalah Gizi yang Ancam Remaja Indonesia. Jakarta: Kementerian Kesehatan RI; 2018. Tersedia pada: www.depkes.go.id (Diakses: 5 Maret 2019).

8. Kemenkes. Menkes: Mari Bersama Sukseskan GERMAS dan Keluarga Sehat. Jakarta: Kementerian Kesehatan RI; 2016. Tersedia pada: http://www .depkes.go.id/article/view/16040400003/me nkes-mari-bersama-sukseskan-germas-dankeluarga-sehat.html (Diakses: 20 Maret 2019).

9. Abrori dan Qurbaniah, M. Infeksi Menular Seksual. Pontianak: UM Pontianak Press; 2017.

10. Notoatmodjo, S. Kesehatan Masyarakat Ilmu dan Seni Edisi Revisi 2011. Jakarta: Rineka Cipta; 2012.

11. Supratman, L.P. dan Mahadian, A. B. Psikologi Komunikasi. Yogyakarta: Deepublish; 2018.

12. Sibagariang, I. T. Pengaruh Penyuluhan Tentang Sayur dan Buah dengan Metode Ceramah dan Bermain Tebak Rasa terhadap Pengetahuan dan Sikap Dalam Konsumsi
Sayur dan Buah Pada Siswa Sd Negeri 067254 Kecamatan Medan Deli Tahun 2016. Medan.; 2016

13. Rahayu, A. S, dkk. Perbedaan Praktik Konsumsi Sayur dan Buah Melalui Edukasi Gizi Ceramah-Cooking Class (Studi di Sekolah Dasar Al Uswah Bangil Pasuruan). J Gizikes. 2016; 2(2).

14. Honggowiyono, P. Pertumbuhan dan Perkembangan Peserta Didik Untuk Guru dan Calon Guru. Malang: Gunung Samudera; 2015.

15. Gustiara, I. Konsumsi Sayur dan Buah pada Siswa SMA Negeri 1 Pekanbaru, J Precure. 2017; 1.

16. Alhamda, S. Buku Ajar Sosiologi Kesehatan. Jakarta: Kencana; 2015.

17. Maulana, H. D. J. Promosi Kesehatan Edisi I. Jakarta: EGC; 2009

18. Virlita dkk. Persepsi Kebiasaan Konsumsi Serat pada Remaja SMP dan SMA Kota Palembang Tahun 2013. J Ilmu Kesehatan Masyarakat. 2015; 6(2).

19. Nugraheni, H., dkk. Kesehatan Masyarakat dalam Determinan Sosial Budaya. Yogyakarta: Deepublish; 2018.

20. Bensley, R. J. dan Fisher, J. B. Metode Pendidikan Kesehatan Masyarakat. Jakarta: EGC; 2009.

21. Kemenkes. Rajin Cek Kesehatan, Kebiasaan Cerdik Cegah Penyakit Tidak Menular. Jakarta: Kementerian Kesehatan RI; 2016. Tersedia pada: http://www.depkes.go.id/development/site/ depkes/index.php?cid=1-16100 600008\&id=rajin-cek-kesehatan-kebiasaancerdik-cegak-penyakit-tidak-menular (Diakses: 20 Februari 2019).

22. Kemenkes. Modul Pelatihan Pelayanan Kesehatan Peduli Remaja. Jakarta: Kementerian Kesehatan RI; 2011. 